Running title: Loss of FKBP5 affects neuron synaptic plasticity

\title{
Loss of FKBP5 affects neuron synaptic plasticity: an electrophysiology insight
}

Bin Qiu ${ }^{1, *}$, Yuxue $X u^{1}{ }^{1, *}$, Jun Wang ${ }^{1,3}$, Ming Liu ${ }^{1}$, Longyu Dou ${ }^{1}$, Ran Deng ${ }^{1}$, Chao Wang ${ }^{1}$, Kent E. Williams ${ }^{2}$, Robert B. Stewart ${ }^{4}$, Zhongwen Xie ${ }^{3}$, Wei Ren ${ }^{6}$, Zhenwen Zhao ${ }^{6}$, Weinian Shou ${ }^{5}$, Tiebing Liang ${ }^{2, \#}$, Weidong Yong ${ }^{1, \#}$

${ }^{1}$ Comparative Medical Center, Institute of Laboratory Animal Science, Chinese Academy of Medical Sciences \& Peking Union Medical College, Beijing 100021, China

${ }^{2}$ Department of Medicine, Indiana University School of Medicine, Indianapolis, Indiana 46202, USA

${ }^{3}$ College of Life Sciences, Anhui Agricultural University, Hefei, Anhui 230036, China ${ }^{4}$ Department of Psychology, Purdue School of Science, Indiana University-Purdue University of Indianapolis, Indianapolis, Indiana 46202, USA

${ }^{5}$ Herman B Wells Center for Pediatric Research, Department of Pediatrics, Indiana University School of Medicine, Indianapolis, Indiana, USA;

${ }^{6}$ Key Laboratory of Analytical Chemistry for Living Biosystems, Institute of Chemistry Chinese Academy of Sciences, Beijing 100190, China

* These authors contributed equally to this work.

\# Correspondence should be addressed to:

- Weidong Yong, Ph.D. Institute of Laboratory Animal Science

Chinese Academy of Medical Sciences \& Peking Union Medical College Beijing 100021, China

Tel/fax: +861067762060

Email: wyong@cnilas.org or yongwd@hotmail.com

- Tiebing Liang, Ph.D.

Indiana Alcohol Research Center

Department of Medicine Indiana University, School of Medicine Indianapolis, IN 46202, USA

Tel: +13172747813

Fax: +13172742695

Email: tliang@iu.edu

\section{Keywords}

Fkbp5 KO, GABAergic, Glutamatergic, LTP, Synaptic Plasticity 


\section{Abstract}

FKBP5 (FKBP51) is a glucocorticoid receptor (GR) binding protein, which acts as a co-chaperone of heat shock protein 90 (HSP90) and negatively regulates GR. Its association with mental disorders has been identified, but its function in disease development is largely unknown. Long-term potentiation (LTP) is a functional measurement of neuronal connection and communication, and is considered one of the major cellular mechanisms that underlies learning and memory, and is disrupted in many mental diseases. In this study, a reduction in LTP in Fkbp5 knockout (KO) mice was observed when compared to WT mice, which correlated with changes to the glutamatergic and GABAergic signaling pathways. The frequency of mEPSCs was decreased in KO hippocampus, indicating a decrease in excitatory synaptic activity. While no differences were found in levels of glutamate between KO and WT, a reduction was observed in the expression of excitatory glutamate receptors (NMDAR1, NMDAR2B and AMPAR), which initiate and maintain LTP. The expression of the inhibitory neurotransmitter GABA was found to be enhanced in Fkbp5 KO hippocampus. Further investigation suggested that increased expression of GAD65, but not GAD67, accounted for this increase. Additionally, a functional GABAergic alteration was observed in the form of increased mIPSC frequency in the KO hippocampus, indicating an increase in presynaptic GABA release. Our findings uncover a novel role for Fkbp5 in neuronal synaptic plasticity and highlight the value of Fkbp5 $\mathrm{KO}$ as a model for studying its role in neurological function and disease development. 


\section{Introduction}

FKBP5 (FK506-binding protein 51, also known as FKBP51) belongs to a subclass of immunophilin proteins and exhibits peptidyl-prolyl cis-trans isomerase (PPlase) activity crucial for protein folding (Schiene and Fischer 2000). It functions as a co-chaperone of heat shock protein 90 (HSP90) and forms a glucocorticoid receptor (GR) complex with additional components (Reynolds, Ruan et al. 1999, Westberry, Sadosky et al. 2006, Stechschulte and Sanchez 2011). Previous research revealed that FKBP5 is highly expressed in the hippocampus (Scharf, Liebl et al. 2011) and it appears to be essential for hypothalamic-pituitary-adrenal (HPA) axis function, including the physiological stress response that shapes neuroendocrine reactivity and coping behavior (Binder 2009, Costin, Wolen et al. 2013). In humans, single nucleotide polymorphisms (SNPs) within the FKBP5 gene are associated with increased recurrence of depressive episodes and increased susceptibility to post-traumatic stress disorder (PTSD), bipolar disorder, major depressive disorder, and suicide attempts (Binder, Salyakina et al. 2004, Binder, Bradley et al. 2008, Lekman, Laje et al. 2008, Tatro, Everall et al. 2009, Willour, Chen et al. 2009, Costin, Wolen et al. 2013, Ellsworth, Moon et al. 2013, Szczepankiewicz, Leszczynska-Rodziewicz et al. 2014). FKBP5 has also been implicated in the development of addiction and PTSD-alcohol use disorder comorbidity (Xie, Kranzler et al. 2010, McClintick, Xuei et al. 2013, Levran, Peles et al. 2014), as well as alcohol consumption (Qiu, Luczak et al. 2016) and alcohol withdrawal severity (Huang, Schwandt et al. 2014). 
The associations of FKBP5 with these conditions suggests a critical role in neuroadaptation following stress, alcohol, or other insults. Animal studies have revealed that Fkbp5 mRNA expression is increased in the hippocampus following the stress of chronic social defeat (Wagner, Marinescu et al. 2012) and increased in the paraventricular nucleus (PVN) and central amygdala (CeA) following restraint stress (Scharf, Liebl et al. 2011). Our studies have found that relative to WT mice, Fkbp5 $\mathrm{KO}$ mice consume more alcohol and suffer more severe alcohol withdrawal as measured by handling-induced convulsions (HICs) following both acute and chronic alcohol exposure (Huang, Schwandt et al. 2014, Qiu, Luczak et al. 2016). The expression level of FKBP5 has been correlated with several mental illnesses (Ising, Depping et al. 2008, Lekman, Laje et al. 2008, Binder 2009, Levran, Peles et al. 2014), and is responsive to stress, alcohol, and morphine (Treadwell and Singh 2004, McClung, Nestler et al. 2005, Balsevich, Uribe et al. 2014). Even though elimination of Fkbp5 has been found to elicit some behavioral changes (Hartmann, Wagner et al. 2012), electrophysiological examination and molecular analyses are necessary to ascertain differences in neuronal function and neurotransmitter regulation, respectively.

Long-term potentiation (LTP) is critical in learning and memory, and its dysfunction underlies many mental diseases. LTP is defined as an increase in postsynaptic responses lasting hours to days following a high-frequency activation of excitatory synapses (Bliss and Gardner-Medwin 1973, Bliss and Lomo 1973), and is thought to be the functional basis underlying memory formation (Bliss and Collingridge, 1993; Bliss et al., 2014). In addition to variations in LTP, differences in neurotransmitter activity, particularly the glutamatergic (Nakanishi 1994, Swanson, Bures et al. 2005, Gos, Gunther et al. 2009) and GABAergic (Saba, Bennett et al. 
2011) systems require investigation to understand brain function. A variety of NMDA receptor subunits have been identified: the ubiquitously expressed NR1 subunit; a family of four distinct NR2 subunits (A, B, C, and D); and two NR3 subunits (Moriyoshi, Masu et al. 1991, Sugihara, Moriyoshi et al. 1992, Das, Sasaki et al. 1998). All NMDARs appear to function as heteromeric assemblies composed of multiple NR subunits (Das, Sasaki et al. 1998). NMDAR1 is necessary for plasticity in the CA1 region (McHugh, Blum et al. 1996, Tsien, Huerta et al. 1996). Deletion of NR2B is associated with impairment of LTP in hippocampus (Li, Erzurumlu et al. 1994, Kutsuwada, Sakimura et al. 1996), conversely, overexpression of NR2B enhances LTP and has been shown to enhance learning and memory (Tang, Shimizu et al. 1999). In addition, activation of the GABAergic system, particularly enhanced GABA release and GABA receptor trafficking, contributes to alcohol consumption (Enoch 2008, Saba, Bennett et al. 2011) and other mental illnesses (Sajdyk, Johnson et al. 2008, Luscher, Shen et al. 2011, Abdallah, Jackowski et al. 2015). GABA synthesis may also play a key role in maintaining a high level of GABA activity. However, these signaling systems have not previously been studied in Fkpb5 KO mice, and little is known about the overall impact of Fkbp5 on synaptic output, which may be crucial for understanding its role in disease development. In this study we have examined LTP function in Fkbp5 KO and WT mice, and measured alterations in the GABAergic and glutamatergic systems. The levels of Glutamate and GABA were measured, and NMDA receptor expression levels and GABA synthesis enzymes were quantified. Behavioral differences were also measured.

\section{Materials and Methods}

\section{Animals}


All experimental protocols were reviewed and approved by the Animal Care and Research Advisory Committee in the Institute of Laboratory Animal Sciences, Chinese Academy of Medical Sciences, and the Indiana University School of Medicine. The animals were maintained in facilities fully accredited by the Association for the Assessment and Accreditation of Laboratory Animal Care (AAALAC). Development of Fkbp5 knockout (Fkbp5 KO) mice was described in a previous publication (Yong, Yang et al. 2007). Fkbp5 KO and WT littermates were bred through heterozygous mating and were back crossed to $\mathrm{C} 57 \mathrm{BL} / 6 \mathrm{~J}$ inbred mice for at least 5 generations.

\section{Brain slice preparation for electrophysiological measurement}

Brain slices for electrophysiology were prepared from WT and KO male mice at 8 weeks of age as described previously (Hou et al., 2006). In brief, mice were deeply anaesthetized and brains were rapidly removed from the skull and transferred into ice-cooled artificial cerebrospinal fluid (ACSF) (in mM: $125 \mathrm{NaCl}, 2.5 \mathrm{KCl}, 1.25$ $\mathrm{NaH}_{2} \mathrm{PO}_{4}, 25 \mathrm{NaHCO}_{3}, 10 \mathrm{D}-\mathrm{Glucose}, 2.5 \mathrm{CaCl}_{2}$, and $1.5 \mathrm{MgCl}_{2}$ ) and saturated with $95 \% \mathrm{O}_{2}$ and $5 \% \mathrm{CO}_{2}$ at $\mathrm{pH}$ 7.3. Transverse slices of $400 \mu \mathrm{m}$ thickness containing the hippocampus were cut with a Vibratome (Leica, VT 1000 S, Germany), which was filled with cold ACSF. The prepared slices were incubated in oxygenated ACSF at room temperature for at least 1 hour before being transferred to a recording chamber and bubbled with oxygenated ACSF at $32 \pm 1^{\circ} \mathrm{C}$.

\section{Recording Long term synaptic plasticity response}

Field excitatory postsynaptic potential (fEPSP) population responses were evoked by stimulation in the radiatum with a bipolar electrode placed on the CA3 area using acute brain slices (two slices per animal) prepared from WT $(\mathrm{N}=3)$ and 
$\mathrm{KO}(\mathrm{N}=3)$ male mice at 8 weeks of age; a total of 6 recordings from each genotype. Extracellular recording electrodes were filled with $2 \mathrm{M} \mathrm{NaCl}$ and placed in the stratum radiatum of $\mathrm{CA} 1$. Data were digitized at $3 \mathrm{kHz}$ using an Axopatch $700 \mathrm{~B}$ amplifier and analyzed with Clampfit 10.5 software. Single test pulses at a stimulation intensity that elicited $40 \%$ of a maximal response of fEPSP slope were delivered as the baseline level. The slices were stimulated with single test pulses every $30 \mathrm{~s}$ for at least $30 \mathrm{~min}$ followed by Theta-burst stimulation (TBS) and $60 \mathrm{~min}$ of test stimulation without changing intensity. All TBS contained 10 bursts at $200 \mathrm{~ms}$ inter-stimulation intervals, in which one burst consisted of four pulses of $100 \mathrm{~Hz}$, repeated 3 times with $10 \mathrm{~s}$ inter-stimulation intervals. The time course of changes in the fEPSP slope was calculated in relation to the signals obtained during the last 10 min prior to TBS (100\%), normalizing all responses to this baseline and then averaging across experiments. The degree of LTP was expressed as a percentage of the original control level. All changes in long-term synaptic plasticity were evaluated by averaging the 10 responses at 51-60 min post-TBS and comparing these data to the 10 control signals during the 10 min prior to TBS. All data are presented as means \pm SEM. Student's t-test was performed for statistical evaluation of the data.

\section{Analysis of L-glutamic acid content in hippocampus using LC-MS/MS}

Both sides of hippocampi $(10 \mathrm{mg})$ from WT $(n=3)$ and $\mathrm{KO}(\mathrm{n}=3)$ were homogenized with $800 \mu \mathrm{L}$ of $80 \%$ acetonitrile (containing $0.2 \%$ formic acid and $5 \mathrm{mM}$ ammonium formate) and further extracted by ultrasonication for $5 \mathrm{~min}$. After vortex and centrifugation at $13,225 \mathrm{~g}$ for $10 \mathrm{~min}$ at room temperature, the supernatants were collected for L-glutamic acid measurement. Aliquots of $5 \mu \mathrm{L}$ were injected onto the LC-MS/MS system. Liquid chromatography was performed with the LC system (I- 
class Acquity ultra performance liquid chromatography, Waters) including an autosampler and ultra-high performance binary pump. MS/MS detection was performed on an API 4500 QTRAP mass spectrometer (Applied Biosystems/MDS SCIEX) equipped with a heated electrospray ionization (ESI) source operated in the positive ionization mode. Nitrogen was used as the nebulizer and desolvation gases. Typical operating parameters were set as follows: curtain gas (CUR) 10, collision gas (CAD) medium, temperature $300^{\circ} \mathrm{C}$, ion source gas 1 (GS1) 45, ion source gas 2 (GS2) 50, and electrospray voltage $5500 \mathrm{~V}$. The ion transitions were $\mathrm{m} / \mathrm{z}$ $148.1 \rightarrow 84.0$ for L-glutamic acid (collision energy $=21 \mathrm{~V}$ ). The peak areas of different concentrations of L-glutamic acid $(0.008 \mathrm{ng} / \mathrm{mL}-20 \mathrm{ng} / \mathrm{mL}$, Sigma-Aldrich, Saint Louis, MO, USA) analyzed by QTRAP 4500 were collected to establish standard curves and further calculate the concentrations of each analyte in real samples.

\section{Western blotting analysis}

Hippocampi were harvested on ice in lysis buffer (Beyotime, Jiangsu, China) with 1:10 volume of protease inhibitor (S8800, Sigma-Aldrich, Saint Louis, MO, USA) and 1:100 volume of phosphatase inhibitor cocktail (P0044, Sigma-Aldrich, Saint Louis, MO, USA). After centrifugation, the supernatants were collected and protein concentrations were determined using a BCA kit (Beyotime, Jiangsu, China). The samples were mixed with loading buffer and denatured. Proteins (40 $\mu \mathrm{g}$ each lane) were separated by $10 \%$ sodium dodecyl sulfate (SDS)-polyacrylamide gels (Tanon equipment) and electrically transferred onto a nitrocellulose membrane $(0.2 \mu \mathrm{m})$ (Pall Corporation, Ann Arbor, MI). Membranes were blocked prior to immunoblotting with primary antibodies at $4^{\circ} \mathrm{C}$ overnight. Blots were then incubated with HRP-conjugated secondary antibodies (1:5000, Santa Cruz, CA) and proteins were detected using ECL western blotting reagent kits. Signals were monitored by the Tanon 5500 
Chemiluminescent Imaging System (Tanon, Shanghai, China) and quantified using TanonGis software (Tanon, Shanghai, China). Density values were normalized to GAPDH signal and provided as the mean \pm SEM. Antibodies used in this study: antiAMPA (1:500), anti-NMDAR1 (1:500), anti-NMDAR2B (1:1000), anti-GAD65 (1:500), anti-GAD67 (1:500), and anti-GAT1 (1:1000) antibodies were purchased from Abcam (Cambridge, UK). HRP-conjugated anti-GAPDH (1:5000) was purchased from KangChen Bio-tech, Inc. (Shanghai, China).

\section{Immunolabeling of brain slices}

Immunohistochemical $(\mathrm{IH})$ labeling of brain slices from male mice at 8 weeks of age of both WT (N=3) and KO (N=3) were performed as previously described (Bin Qiu, 2016). Anti-GABA (1:200) antibody was purchased from Abcam (Cambridge, UK).

For immunofluorescence (IF), male mice at 8 weeks age of both WT $(\mathrm{N}=3)$ and KO $(N=3)$ genotypes were anesthetized with an i.p. injection of tribromoethanol (20 $\mathrm{mg} / \mathrm{ml}, 0.018 \mathrm{ml} / \mathrm{g} \mathrm{BW})$, and perfused transcardially with PBS $\left(\mathrm{pH} 7.4,4^{\circ} \mathrm{C}\right)$ followed by $4 \%$ paraformaldehyde $\left(\mathrm{pH} 7.4,4^{\circ} \mathrm{C}\right)$. The brains were isolated, embedded in OCT, and sectioned at $10 \mu \mathrm{m}$ thickness using a cryostat microtome (Leica CM3050S, Germany). Slices were mounted on 3-aminopropyltriethoxysilane (APES) coated slides, blocked, and incubated with primary antibodies overnight at $4^{\circ} \mathrm{C}$ and secondary antibodies for $1 \mathrm{~h}$ at $37^{\circ} \mathrm{C}$. Nuclei were stained with DAPI mounting media (Zhongshan Goldenbridge Biotechnology, China). The fluorescence signal was captured using confocal laser scanning microscopy (Leica TCS LSI, Germany). The antibodies used in these experiments include rabbit anti-NMDAR1 (1:25), rabbit antiNMDAR2B (1:25), rabbit anti-AMPAR (1:25), rabbit anti-GABA, and Alexa Flour® 488-conjugated goat anti-Rabbit IgG (1:500) from Abcam (Cambridge, UK). The optical density (AOD) of GABA was quantified by ImageJ. 


\section{Recording of miniature excitatory postsynaptic currents}

Miniature excitatory postsynaptic currents (mEPSCs) of CA1 pyramidal cells were recorded in whole cell mode using acute brain slices (two slices per animal) prepared from $\mathrm{WT}(\mathrm{N}=4)$ and $\mathrm{KO}(\mathrm{N}=4)$ male mice at 8 weeks of age as described above; a total of 8 recordings per genotype. The electrophysiological recordings were obtained under visual control by use of an Olympus microscope (Olympus BX50-WI, Olympus, Japan) and a 40x long-working distance objective (NA 0.8). Patch pipettes with 4-6 $\mathrm{M} \Omega$ resistance were pulled from $110 \mathrm{~mm}$ long borosilicate glass capillaries (GB 150F-86-10, Sutter instrument, USA). The ion currents were recorded by an Axopatch 700B amplifier and pClamp10.6. Only cells that showed a high seal resistance $(>1 \mathrm{G} \Omega$ ) and a series resistance $<25 \mathrm{M} \Omega$ were included. The series- and input-resistances were checked before and after the recordings in each experimental sequence. Cells were excluded if the input resistance or series resistance changed more than $15 \%$ throughout the experiment. Signals were obtained at a holding potential of $-70 \mathrm{mV}$. For pharmacological isolation of AMPA receptor-mediated mEPSCs, $1 \mu \mathrm{M}$ Tetradotoxin (TTX, the voltage-gated sodium channel blocker) and $100 \mu \mathrm{M}$ picrotoxin (PTX, GABAA receptor antagonist) were added to the ACSF to abolish action potentials and inhibitory postsynaptic current events, respectively. The intracellular solution consisted of the following: (in mM) 140 K-gluconate, $2 \mathrm{MgCl}_{2}, 8 \mathrm{KCl}, 10 \mathrm{HEPES}, 0.2 \mathrm{NaGTP}$, and $2 \mathrm{Na}_{2} \mathrm{ATP}$. The $\mathrm{pH}$ was adjusted to 7.3 with $\mathrm{KOH}$. For each cell, at least 5 minutes of recording was obtained. For the detection of spontaneous events, the "threshold research" option was used and each event was checked. Data were analyzed off-line by using pClamp10.6 for event Frequency and Amplitude. Unpaired t-test was used for 
statistical analysis. Results are presented as mean \pm SEM, and significance was defined as $p<0.05$.

\section{Recording of miniature inhibitory postsynaptic currents}

Miniature inhibitory postsynaptic currents (mIPSCs) of CA1 pyramidal cells were recorded in whole cell mode using acute brain slices (two slices per animal) prepared from $\mathrm{WT}(\mathrm{N}=4)$ and $\mathrm{KO}(\mathrm{N}=4)$ male mice at 8 weeks of age as described above. The signal was obtained at a holding potential of $-70 \mathrm{mV}$. For pharmacological isolation of $\mathrm{GABA}_{A}$ receptor-mediated spontaneous inhibitory postsynaptic currents, 10nM glycine, $20 \mu \mathrm{M}$ DNQX (AMPA receptor antagonist), 25 $\mu \mathrm{M}$ D-AP-5 (NMDA receptor antagonist), and 0.5 $\mu \mathrm{M}$ TTX were added to the ACSF. The intracellular solution consisted of the following: (in mM) $135 \mathrm{CsCl}, 10 \mathrm{HEPES}, 2$ $\mathrm{MgCl}_{2}, 20 \mathrm{TEACl}$, and $10 \mathrm{EGTA}$. The $\mathrm{pH}$ was adjusted to 7.3 with $\mathrm{CsOH}$ with a pipette resistance of $4-5 \mathrm{M} \Omega$. The non-parametric Mann-Whitney $U$ test was performed for mIPSC statistical analysis. Results are presented as mean \pm SEM and $p<0.05$ was considered significant. Cumulative distribution plots of mIPSC amplitudes and inter-event intervals were compared using the Kolmogorov-Smirnov Goodness of Fit Test.

\section{Saccharin and quinine consumption test and the forced swimming test (FST)}

Saccharin and quinine intake was tested in adult male $\mathrm{KO}(\mathrm{N}=14)$ and $\mathrm{WT}(\mathrm{N}=21)$ mice. Animals were individually caged with free choice of water and $1.03 \%$ (W/V) saccharin. Fluid intake was recorded twice during the 1 week test (Pelz, Whitney et al. 1973). Forced swimming test was performed using 3-month-old male KO $(\mathrm{N}=12)$ and WT (N=12) mice. Animals were individually placed in a 2-Liter glass beaker filled with water $\left(22 \pm 1^{\circ} \mathrm{C}\right)$ to a height of $15 \mathrm{~cm}$, so that the mouse could neither touch the 
bottom nor escape. The test lasted for $5 \mathrm{~min}$ and the time spent floating versus struggling was recorded. The 'floating behavior' (where the animal remains almost immobile and with its head above water) was used as a parameter to analyze behavioral differences.

\section{Statistical analysis}

Unless otherwise noted, all values are presented as mean \pm standard error of the mean (SEM). Differences between two groups were compared by Student's t-test with GraphPad Prism (GraphPad Software Inc., San Diego, CA). P values less than 0.05 were considered to be significant.

\section{Results}

\section{LTP is decreased in Fkbp5 KO hippocampus}

Responses to drugs and stress often present with aberrations in LTP, which may indicate the activation of a common substrate, resulting in alterations of synaptic strength (Nestler 2001, Wolf 2003, Niehaus, Murali et al. 2010). To investigate whether elimination of the Fkbp5 gene produces dysfunctions in LTP, electrophysiological testing was carried out on brain slices of WT and Fkbp5 KO mice. Stimulation electrodes were placed in the CA3 region of the hippocampus, and recording electrodes were placed in CA1 (Figure 1A), producing a typical change in evoked responses following LTP. Field excitatory postsynaptic potentials (fEPSPs) were recorded in the hippocampi of both WT and KO mice (Figure 1B and 1C). Relative to WT, the fEPSP slope was significantly lower in KO following TBS stimulation (Figure 1D). The bar graphs summarize the differences in percentage of fEPSP slope before and after TBS (Figure 1E). The data indicate that KO mice display significant reductions in LTP. 


\section{Decreased expression of glutamate receptors in Fkbp5 KO hippocampus}

Classical synaptic LTP requires glutamate and NMDA receptor (NMDAR) activation, which drives increased AMPA receptor (AMPAR) expression in the postsynaptic membrane (Bashir, Bortolotto et al. 1993). NMDA receptor activation occurs when it binds with glutamate and glycine (or D-serine), allowing positively charged ions to flow through the cell membrane. To determine the source of the reduced LTP observed in $\mathrm{KO}$, we first measured the glutamate level in the hippocampi of KO and WT mice. However, no differences of glutamate content, measured by L-glutamic acid, were observed (Figure 2A). Further analyses were conducted to determine whether the observed reductions in LTP are associated with alterations in excitatory glutamate receptors in Fkbp5 KO mice. Indeed, significant reductions in NMDAR1, NMDAR2B, and AMPAR protein expression in the hippocampus were identified in Fkbp5 KO mice via Western blot (Figure 2B-D). Concurrent results were evident in immunofluorescence (IF) labeling. The majority of neurons in the CA1 and DG sub-regions displayed an abundance of NMDAR1 (Figure 2E), NMDAR2B (Figure 2F), and AMPAR (Figure 2G) expression in WT mice, while the expression of these proteins was considerably reduced in Fkbp5 KO mice (Figure 2E-G). These results suggest that the decreased LTP observed in Fkbp5 KO mice may be partially due to lower expression levels of excitatory glutamate receptors

\section{Decreased frequency of mEPSCs in Fkbp5 KO mice}

Given the lack of change in glutamate abundance coupled with decreased expression of glutamate receptors in Fkbp5 KO hippocampus, we next investigated the functional glutamatergic synapse alterations in $\mathrm{KO}$ hippocampus, particularly 
those that might account for the observed attenuation of LTP. At a holding potential of $-70 \mathrm{mV}$, AMPA receptor-mediated mEPSCs were monitored with the addition of

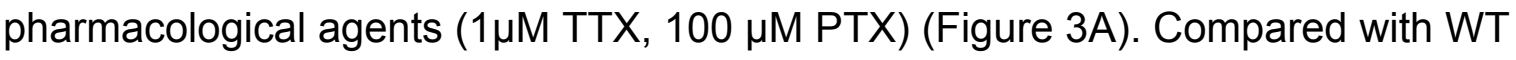
mice, the mEPSC frequency was significantly lower in KO mice (WT: $2.31 \pm 0.18 \mathrm{~Hz}$; $\mathrm{KO}: 1.33 \pm 0.15 \mathrm{~Hz}, p<0.001$, Unpaired t-test) (Figure 3B and 3C), but no differences were observed in mEPSC amplitude (WT: $18.89 \pm 1.15 \mathrm{~Hz}$; KO: $17.23 \pm$ $1.44 \mathrm{~Hz}, p=0.3809$, Unpaired t-test) (Figure 3D and 3E). A reduced mEPSC frequency is usually interpreted as a decrease in the presynaptic release probability, however this is not consistent with the similar glutamate content observed between the WT and KO. An alternative explanation for the lower mEPSC frequency observed in $\mathrm{KO}$ is a reduction in the number of functional synaptic sites, which is consistent with the decreased expression of glutamate receptors in $\mathrm{KO}$. Moreover, the lack of difference in the amplitude of the mEPSCs between WT and KO indicates a lack of change in the activation of the postsynaptic glutamate receptors that are present. Taken together, the reduced LTP in KO is likely due to a decreased number of functional excitatory synaptic sites, but is not associated with a change in the activation of postsynaptic glutamate receptors.

\section{Increased GABA level in Fkbp5 KO hippocampus}

Normal central nervous system function requires maintaining a balance between neuronal excitation and inhibition. Because GABA is the major inhibitory transmitter in the CNS, we examined GABA in Fkbp5 KO mice via IHC labeling. An increase in GABA was detected in the KO hippocampus relative to WT (Figure 4A and 4B). The magnified CA1, CA2, CA3, and DG sub-regions also displayed these differences, which were quantified (Figures 4C). In line with the observed increase in KO hippocampal GABA level, KO mice exhibited an increase in the expression of 
GAD65 (also known as glutamate decarboxylase 2), an enzyme that catalyzes the decarboxylation of glutamate to GABA (Figure 5A). In addition to GAD65, KO mice also appeared to possess a slightly higher expression of another enzyme, GAD67 (also known as glutamate decarboxylase 1), although this difference did not reach statistical significance (Figure 5B). Likewise, no significant difference in GABA transporter GAT1 expression could be detected between KO and WT (Figure 5C). These results provide evidence in support of enhanced GABA production in the presynaptic terminal partially via increased GAD65 enzyme in Fkbp5 KO mice.

\section{Increased frequency of mIPSCs in Fkbp5 KO mice}

Based on the observed increase in GABA level, we next investigated the functional GABAergic alterations present in KO hippocampus, to determine whether such alterations could account for the previously observed attenuation of LTP. Hippocampal slices obtained from animals at 8 weeks of age were assessed using whole cell recording techniques. At a holding potential of $-70 \mathrm{mV}$, miniature IPSCs (mIPSCs) were detected as fast inward currents, which could be blocked by application of $10 \mu \mathrm{M}$ bicuculline, a competitive $\mathrm{GABA}_{\mathrm{A}}$ receptor antagonist (Figure $6 A)$. This result indicated that the mIPSCs were mediated via $\mathrm{GABA}_{A}$ receptor activation. Cumulative probability analysis revealed a significant reduction in mIPSC inter-event intervals, indicating an increased frequency of these signals in $\mathrm{KO}$ mice $(11.5 \pm 1.2 \mathrm{~Hz})$ when compared to WT $(8.2 \pm 0.5 \mathrm{~Hz}, p<0.05$, Kolmogorov-Smirnov (KS)) (Figure 6B and 6C). However, the amplitudes of the mIPSCs demonstrated no significant differences between the two groups (KO: $21.17 \pm 1.35$ pA; WT: $21.2 \pm 1.13$ $\mathrm{pA}, p=0.99)$ (Figure 6D and 6E). The increased frequency of mIPSCs in Fkbp5 KO mice is consistent with increased GABAergic synaptic activity and could indicate a change in the probability of transmitter release. This is in agreement with the 
observed increase in KO hippocampal GABA. The unchanged amplitude of mIPSCs suggests that postsynaptic function is apparently unaffected.

\section{Fkbp5 KO male mice display behavior differences compared to WT mice}

SNPs in the FKBP5 gene have been associated with PTSD, depression, anxiety, and bipolar disorder (Binder, Bradley et al. 2008, Willour, Chen et al. 2009, Tatro, Nguyen et al. 2010). Given these associations and the role of GABAergic signaling in these illnesses, it was important to examine behavioral differences between male WT and Fkbp5 KO mice. Depression-like behavior was assessed using an anhedonia test and the forced swim test (Porsolt, Le Pichon et al. 1977, Lucki 1997). When given free access to water and saccharin, KO male mice exhibited reduced total saccharin consumption via t-test $(p<0.01)$ (Figure 7A); and this difference was not due to differences in taste sense as measured by quinine intake (Figure 7B). These results indicate that Fkbp5 KO male mice display decreased anhedonic behavior. FST has been used to assess the effects of genetic modification on depressive behavior in animals (Porsolt et al., 1977) or the learned immobility to adapt successfully to the inescapable situation (Cryan and Mombereau, 2004). Male KO mice spent significantly more time floating than WT by t-test ( $p=$ 0.01) (Figure 7C).

\section{Discussion}

FKBP5 plays an important role in various mental illnesses, including PTSD, anxiety, depression, and addiction. It also has important effects on signaling pathways and neuron development. Its role in the homeostatic plasticity of the glutamatergic and GABAergic systems has not previously been explored. In the present study, we discovered that mice lacking Fkbp5 exhibit reduced LTP, 
associated with decreased mEPSCs and increased GABAergic synaptic function in the hippocampus. Saccharin consumption and FST behaviors were found to be impacted in the $\mathrm{KO}$ male mice. Our findings uncover a role for Fkbp5 in neuronal synaptic plasticity and highlight the value of $F k b p 5 \mathrm{KO}$ as a model for studying neurological disease.

It has been established that the induction of LTP in the CA1 area of the hippocampus requires glutamate and the activation of NMDA receptors located in the cell membrane of the postsynaptic neuron. NMDA influx triggers an increase in calcium entry, leading to activation of postsynaptic molecular pathways, and increased postsynaptic AMPAR density, which is responsible for a persistent increase in the postsynaptic response (Bliss \& Collingridge, 1993). In this study, a reduction of LTP was observed in Fkbp5 KO mice, suggesting altered neural function in the Fkbp5 KO hippocampus. As no differences in glutamate abundance were observed between WT and $\mathrm{KO}$, and a reduction in the expressions of excitatory receptors (NMDAR1, NMDAR2B, and AMPAR) were found in $\mathrm{KO}$, we conclude that the synthesis of glutamate is not altered in the ablation of Fkbp5, and that the reduced LTP may be partially due to reductions of NMDAR1 and NMDAR2B levels in the postsynaptic membrane. Western blotting and immunofluorescence data indicated that Fkbp5 $\mathrm{KO}$ affects the molecular expression of these receptors in hippocampus (Fig. 2), resulting in altered neuronal activity. In addition to NMDA receptors, AMPA receptors on the postsynaptic membrane are required to drive LTP (Isaac, Nicoll et al. 1995, Liao, Hessler et al. 1995). Consistent with our observations, the reduction of AMPAR in Fkbp5 KO may also contribute to reduced LTP. Moreover, a significant decrease in mEPSC frequency was observed in KO 
mice. Reduced mEPSC frequency indicates either a decrease in the presynaptic release probability or a decreased number of functional synaptic sites.

GABAergic activity also plays a fundamental role in the induction of LTP (Wigstrom and Gustafsson 1983). Previous research has demonstrated that increasing doses of the GABA-enhancing diazepam (Riss, Cloyd et al. 2008) inhibits LTP, indicating that GABAergic activity exerts a powerful influence over LTP (Levkovitz, Avignone et al. 1999). In the current study, increased GABA was observed in Fkbp5 KO hippocampus, potentially due to increased GABA synthesis. GABA is primarily synthesized from glutamate by GAD67 and GAD65, which are expressed in different amounts in cell bodies and axon terminals (Erlander, Tillakaratne et al. 1991). GAD67 immunoreactivity is expressed throughout the cell body and in synaptic terminals (Kaufman, Houser et al. 1991), and is a rapidly synthesized and utilized form of GAD, allowing on-site synthesis in response to cellular stimulation (Esclapez, Tillakaratne et al. 1994). In contrast, GAD65 is localized exclusively in the terminals and is reversibly bound to the membrane of synaptic vesicles, which may represent a depot of GAD that can be recruited upon intense stimulation (Kaufman, Houser et al. 1991, Soghomonian and Martin 1998), and plays a specific role in the control of synaptic GABA release (Pinal and Tobin 1998). Indeed, we observed a significant increase in GAD65 expression and a slightly elevated level of GAD67 expression in KO hippocampus, which may account for the higher level of GABA observed in KO mice. The lack of a significant difference in GABA transporter (GAT1) expression suggests that reuptake of GABA is unaffected. The expression of GAD in brain regions of patients suffering from major depressive disorder (MDD) has been investigated previously, with mixed findings in the pre-frontal cortex (PFC), temporal cortex, and thalamus (Bielau, 
Steiner et al. 2007, Gos, Steiner et al. 2012), but some consistent observations of increased density of GAD-IR cells in the entorhinal cortex and the hippocampus (Cheetham, Crompton et al. 1988, Gos, Gunther et al. 2009, Gos, Steiner et al. 2012). In this regard, our results are consistent with human studies in the hippocampus. There are considerable data linking altered GABAergic activity with HPA axis function, in which Fkbp5 plays an important role as a GR regulator. Fkbp5 is highly expressed in brain regions associated with stress response, and responds to stress itself (Scharf, Liebl et al. 2011, Qiu, Luczak et al. 2016). Similarly GAD mRNA expression is enhanced in several hypothalamic regions, such as the dorsomedial hypothalamus, medial preoptic area, and BST (Bowers, Cullinan et al. 1998), following both acute and chronic stress exposure. GR is expressed in the GABAergic neurons of the anterior hypothalamic area and mediates corticosteroidinduced plasticity (Shin, Han et al. 2011). Therefore it is presently unclear whether Fkbp5 affects GAD and GABA directly or indirectly (e.g., via GR). In GAD65 KO mice, reductions in synaptic GABA release are attributable to fewer vesicles being released (Tian et al. 1999). Thus, increased GABA may result from enhanced expression of GAD65 in Fkbp5 KO. This would be consistent with the high frequency of mIPSCs, indicating an increase in presynaptic GABA release. The lack of an effect on mIPSC amplitude in Fkbp5 KO suggests that postsynaptic function is essentially unaffected. Reductions in LTP can be mediated by an increase in presynaptic GABAergic interneurons, due to the increased frequency of mIPSCs (Levkovitz, Avignone et al. 1999). Thus, decreased glutamate receptors and increased GABA may account for the decreased LTP observed in Fkbp5 KO.

GABAergic transmission in the brain has been implicated in the pathophysiology of depressive disorder (Abdallah, Jackowski et al. 2015). GABA 
exerts its major function through the GABA type $A$ receptors (GABA $A_{A}$ ), which inhibit the hyperarousal state and anxiety. Reductions in LTP might be the causal link between FKBP5 SNPs and many mental illnesses (Szymanska, Budziszewska et al. 2009, Tatro, Nguyen et al. 2010, Schmidt, Buell et al. 2015). Previous studies found decreased GABA concentrations in brain regions, such as dorsolateral PFC and occipital cortex (OCC) of patients with MDD (Rajkowska, O'Dwyer et al. 2007, Sanacora and Saricicek 2007, Maciag, Hughes et al. 2010). Recent findings demand more brain region-specific and a more complex models are needed to study this issue (Pehrson and Sanchez 2015). The limitations of human studies make it difficult to evaluate the brain region-specific expression of neurotransmitters and related enzymes, and argue for more animal model research to delineate the regional molecular mechanisms.

In the current study, both anhedonic behavior and FST were found to be impacted in the male KO mice at baseline. Previous research determined that although young $F k b p 5 \mathrm{KO}$ (10-16 week old) mice do not display general behavioral changes at baseline, they spend significantly less time immobile following restraint stress (Touma, Gassen et al. 2011), a behavior also observed in aged Fkbp5 KO (17-20 month old) mice with no stress (O'Leary, Dharia et al. 2011). However, we observed a genotype effect, with unstressed 3-month-old male KO mice spending an increased amount of time floating. This difference could be due to the stress treatment utilized. Although the predominant interpretation of FST is that immobility reflects hopelessness and negative mood (Porsolt et al., 1977), other interpretations are that this may only reflect the acute effect of antidepressants (Mann 2005), or the learned immobility to adapt successfully to the inescapable situation (Cryan and Mombereau, 2004). Our interpretation is that the FST difference may indicate a 
difference in cognitive function (Molendijk and de Kloet 2015). More research is needed to understand Fkbp5 gene function and its effect on learning and memory.

Previous research has demonstrated that GABA and GABAR agonism enhances immobility, indicating that GABAergic functions play some role in the mechanism of this immobility (Nagatani, Sugihara et al. 1984, Nagatani, Yamamoto et al. 1987, Aley and Kulkarni 1989, Ferre, Fernandez Teruel et al. 1994). More recent research found increasing central GABAergic activity using various drugs results in a depressant-like activity, measured as an increase in the duration of immobility in the FST model of depression (EI Zahaf and Salem Elhwuegi 2014). These observations are in line with those of $F k b p 5 \mathrm{KO}$, with higher GABA and enhanced immobility. One limitation of the present study is not having directly tested the manipulation of GABAergic or glutamatergic systems to identify their association with behavior changes. The use of only male mice in the present study represents another limitation, as comparisons between the sexes may have enriched our understanding.

We conclude that FKBP5 plays a critical role in neuronal synaptic plasticity on both excitatory and inhibitory synapses in the hippocampus. Further research into how the elimination of $F k b p 5$ alters neuron development, gene expression, and behavior will provide insights into future treatment strategies for mental illness. 


\section{Acknowledgements}

This research was supported by grants from CAMS Innovation Fund for Medical

3 Sciences (CIFMS) WY (2017-I2M-3-015), the National Science Foundation of China 4 BQ (No.81700751), WY (No. 81272273), and ZX (No.31571207). NIAAA

5 P60AA007611 and R01AA10707 of National Institutes of Health (NIH). We would also

6 like to express our appreciation to Judy E. Powers for technical support, Dr. Brady

7 Atwood for paper revision, and Dr. Lucinda Carr and Dr. Lawrence Lumeng of the

8 Indiana Alcohol Research Center, for their support in providing useful discussions of

9 this research and their wisdom in long-term research using animal models.

10 Conflict of Interest

All authors have no conflict of interest to declare. 


\section{Figure legends}

\section{Figure 1. Fkbp5 KO mice exhibit decreased LTP.}

(A) The anatomical placement of electrodes in the mouse hippocampus for LTP measurement. (B) The LTP (blue) responses of WT mice. (C) The LTP (red) responses of KO mice. (D) The time course of changes in fEPSP slope during LTP measurement. (E) The calculated changes and statistical analysis in fEPSP slope during LTP measurement. All changes in long-term synaptic plasticity were evaluated by averaging 10 responses at 51-60 minutes post- theta-burst stimulation (TBS) and normalizing these data to 10 control signals at 11-20 minutes prior to TBS. Comparisons were made using WT $(\mathrm{N}=3)$ and $\mathrm{KO}(\mathrm{N}=3)$ male mice at 8 weeks of age ; a total of 6 recordings from each genotype. Student's $t$-test was applied statistical significant analysis: ** represents $p<0.01$.

Figure 2. Fkbp5 KO mice possess reduced glutamate receptor expression in the hippocampus.

(A) The content of L-glutamic acid in hippocampus detected using LC-MS/MS by comparing $\mathrm{KO}(\mathrm{N}=3)$ and $\mathrm{WT}(\mathrm{N}=3)$ male mice. $(\mathrm{B}, \mathrm{C}$, and $\mathrm{D})$ The expression of NMDAR1, NMDAR2B, and AMPAR in WT and Fkbp5 KO mouse hippocampus were determined by Western blotting. Data are provided as the mean \pm SEM.

Comparisons were made by Student's t-test: *represents $p<0.05$; ${ }^{* *}$ represents $p<$ 0.01; NS represents no statistical significance. (E, F, and G) The localization and expression of NMDAR1, NMDAR2B, and AMPAR in CA1 and DG sub-regions from WT and KO hippocampus were detected by immunofluorescence. The images within the white rectangles show an enlarged view of the boxed regions. Bar $=100 \mu \mathrm{m}$. 
Figure 3. Decreased frequency of mEPSCs in Fkbp5 KO mice.

(A) Representative signals of AMPA receptor mediated mEPSC recorded at a holding potential of $-70 \mathrm{mV}$. (B) Cumulative probability plots of the mEPSC intervals reveal a shift to the right in the KO curve. (C) The frequency of mEPSCs significantly decreased in $\mathrm{KO}(\mathrm{N}=4)$ compared to WT $(\mathrm{N}=4)$. (D) The cumulative plots of the mEPSC amplitude reveal no differences between the two groups. (E) No significant differences could be detected between the mEPSC amplitudes of the two groups. Comparisons were made by Student's t-test: ${ }^{* * *}$ represents $p<0.001$; NS represents no statistical significance.

\section{Figure 4. Fkbp5 KO mice possess increased GABA level in hippocampus.}

(A) The protein expression of GABA in hippocampus of WT (N=3) and (B) KO (N=3) mice demonstrated by IHC. (C) Comparison of GABA at representative sub-regions of the hippocampus demonstrate a higher level of GABA in the CA1, CA2, CA3, DG1, DG2, and DG3 sub-regions in KO relative to WT. The statistic analysis of the average optical density (AOD) of GABA level that was quantified by ImageJ, and the results were showed as fold change relative to WT. Data are provided as the mean \pm SEM. Comparisons were made by Student's t-test: * ${ }^{* *}$, and ${ }^{* * *}$ represent $p<0.05$, $p<0.01$ and $p<0.001$.

\section{Figure 5. GABA transporter expression in the brain}

(A) The expression of GAD65, (B) GAD67, and (C) GAT1 in the hippocampus from WT $(\mathrm{N}=3)$ and $\mathrm{KO}(\mathrm{N}=3)$ mice determined by Western blotting. Comparisons were made by Student's t-test: * represents $p<0.05$, 
63 Figure 6. Increased frequency of mIPSCs in Fkbp5 KO mice.

64 (A) Representative mIPSC signals recorded at a holding potential of $-70 \mathrm{mV}$ in the

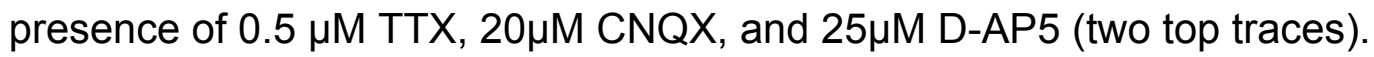
Application of $10 \mu \mathrm{M}$ bicuculline blocks all mIPSCs (two bottom traces) indicating that mIPSCs are mediated by activity from $\mathrm{GABA}_{\mathrm{A}}$ receptors. (B) Cumulative probability plots of the mIPSC intervals reveal a shift to the left in the KO curve. (C) The frequency of mIPSCs was significantly higher in $\mathrm{KO}(\mathrm{N}=4)$ compared to WT $(\mathrm{N}=4)$. (D) The cumulative plots of the mIPSC amplitude reveal no differences between the two groups. (E) No significant differences could be detected between the mIPSC amplitudes of the two groups. Comparisons were made by Student's ttest: *represents $p<0.05$; NS represents no statistical significance.

Figure 7. Fkbp5 KO mice display anhedonic behavior.

(A) Compared to WT male mice $(\mathrm{N}=21)$, Fkbp5 KO mice $(\mathrm{N}=14)$ exhibited a significant reduction in saccharin intake. (B) No significant differences in quinine intake were observed between Fkbp5 KO and WT male mice. (C). Male Fkbp5 KO mice $(\mathrm{N}=12)$ exhibited increased floating time in FST relative to WT $(\mathrm{N}=12)$. Comparisons were made by Student's t-test: * and ${ }^{* *}$ represent $p<0.05$ and $p<$ 0.01 , respectively. 
84

85

86

87

88

89

90

91

92

93

94

95

96

97

98

99

100

101

102

103

104

105

106

107

108

109

110

111

112

113

114

115

Abdallah, C. G., A. Jackowski, J. R. Sato, X. Mao, G. Kang, R. Cheema, J. D. Coplan, S. J. Mathew and D. C. Shungu (2015). "Prefrontal cortical GABA abnormalities are associated with reduced hippocampal volume in major depressive disorder." Eur Neuropsychopharmacol 25(8): 1082-1090.

Aley, K. O. and S. K. Kulkarni (1989). "GABA-mediated modification of despair behavior in mice." Naunyn Schmiedebergs Arch Pharmacol 339(3): 306-311.

Balsevich, G., A. Uribe, K. V. Wagner, J. Hartmann, S. Santarelli, C. Labermaier and M. V. Schmidt (2014). "Interplay between diet-induced obesity and chronic stress in mice: potential role of FKBP51." J Endocrinol 222(1): 15-26.

Bashir, Z. I., Z. A. Bortolotto, C. H. Davies, N. Berretta, A. J. Irving, A. J. Seal, J. M. Henley, D. E. Jane, J. C. Watkins and G. L. Collingridge (1993). "Induction of LTP in the hippocampus needs synaptic activation of glutamate metabotropic receptors." Nature 363(6427): 347-350.

Bielau, H., J. Steiner, C. Mawrin, K. Trubner, R. Brisch, G. Meyer-Lotz, M. Brodhun, H. Dobrowolny, B. Baumann, T. Gos, H. G. Bernstein and B. Bogerts (2007). "Dysregulation of GABAergic neurotransmission in mood disorders: a postmortem study." Ann N Y Acad Sci 1096: $157-169$.

Binder, E. B. (2009). "The role of FKBP5, a co-chaperone of the glucocorticoid receptor in the pathogenesis and therapy of affective and anxiety disorders."

\section{Psychoneuroendocrinology 34 Suppl 1: S186-195.}

Binder, E. B., R. G. Bradley, W. Liu, M. P. Epstein, T. C. Deveau, K. B. Mercer, Y. Tang, C. F. Gillespie, C. M. Heim, C. B. Nemeroff, A. C. Schwartz, J. F. Cubells and K. J. Ressler (2008). "Association of FKBP5 polymorphisms and childhood abuse with risk of posttraumatic stress disorder symptoms in adults." JAMA 299(11): 1291-1305. Binder, E. B., D. Salyakina, P. Lichtner, G. M. Wochnik, M. Ising, B. Putz, S. Papiol, S. Seaman, S. Lucae, M. A. Kohli, T. Nickel, H. E. Kunzel, B. Fuchs, M. Majer, A. Pfennig, N. Kern, J. Brunner, S. Modell, T. Baghai, T. Deiml, P. Zill, B. Bondy, R. Rupprecht, T. Messer, O. Kohnlein, H. Dabitz, T. Bruckl, N. Muller, H. Pfister, R. Lieb, J. C. Mueller, E. Lohmussaar, T. M. Strom, T. Bettecken, T. Meitinger, M. Uhr, T. Rein, F. Holsboer and B. Muller-Myhsok (2004). "Polymorphisms in FKBP5 are associated with increased recurrence of depressive episodes and rapid response to antidepressant treatment." Nat Genet 36(12): 1319-1325. 
116 Bliss, T. V. and A. R. Gardner-Medwin (1973). "Long-lasting potentiation of synaptic

117 transmission in the dentate area of the unanaestetized rabbit following stimulation of the

118 perforant path." J Physiol 232(2): 357-374.

119 Bliss, T. V. and T. Lomo (1973). "Long-lasting potentiation of synaptic transmission in the 120 dentate area of the anaesthetized rabbit following stimulation of the perforant path." $\underline{\mathrm{J}}$

121 Physiol 232(2): 331-356.

122 Bowers, G., W. E. Cullinan and J. P. Herman (1998). "Region-specific regulation of glutamic 123 acid decarboxylase (GAD) mRNA expression in central stress circuits." J Neurosci 18(15): 124 5938-5947.

125 Cheetham, S. C., M. R. Crompton, C. L. Katona, S. J. Parker and R. W. Horton (1988).

126 "Brain GABAA/benzodiazepine binding sites and glutamic acid decarboxylase activity in 127 depressed suicide victims." Brain Res 460(1): 114-123.

128 Costin, B. N., A. R. Wolen, S. Fitting, K. L. Shelton and M. F. Miles (2013). "Role of adrenal 129 glucocorticoid signaling in prefrontal cortex gene expression and acute behavioral responses 130 to ethanol." Alcohol Clin Exp Res 37(1): 57-66.

131 Das, S., Y. F. Sasaki, T. Rothe, L. S. Premkumar, M. Takasu, J. E. Crandall, P. Dikkes, D. 132 A. Conner, P. V. Rayudu, W. Cheung, H. S. Chen, S. A. Lipton and N. Nakanishi (1998).

133 "Increased NMDA current and spine density in mice lacking the NMDA receptor subunit 134 NR3A." Nature 393(6683): 377-381.

135 El Zahaf, N. A. and A. Salem Elhwuegi (2014). "The effect of GABAmimetics on the duration 136 of immobility in the forced swim test in albino mice." Libyan J Med 9: 23480.

137 Ellsworth, K. A., I. Moon, B. W. Eckloff, B. L. Fridley, G. D. Jenkins, A. Batzler, J. M.

138 Biernacka, R. Abo, A. Brisbin, Y. Ji, S. Hebbring, E. D. Wieben, D. A. Mrazek, R. M.

139 Weinshilboum and L. Wang (2013). "FKBP5 genetic variation: association with selective

140 serotonin reuptake inhibitor treatment outcomes in major depressive disorder."

141 Pharmacogenet Genomics 23(3): 156-166.

142 Enoch, M. A. (2008). "The role of GABA(A) receptors in the development of alcoholism." 143 Pharmacol Biochem Behav 90(1): 95-104.

144 Erlander, M. G., N. J. Tillakaratne, S. Feldblum, N. Patel and A. J. Tobin (1991). "Two genes 145 encode distinct glutamate decarboxylases." Neuron 7(1): 91-100.

146 Esclapez, M., N. J. Tillakaratne, D. L. Kaufman, A. J. Tobin and C. R. Houser (1994).

147 "Comparative localization of two forms of glutamic acid decarboxylase and their mRNAs in

148 rat brain supports the concept of functional differences between the forms." J Neurosci 14(3

149 Pt 2): 1834-1855. 
150

151

152

153

154

155

156

157

158

159

160

161

162

163

164

165

166

167

168

169

170

171

172

173

174

175

176

177

178

179

180

181

182

183

184

Ferre, P., A. Fernandez Teruel, R. M. Escorihuela, E. Garcia, A. Zapata and A. Tobena (1994). "Struggling and flumazenil effects in the swimming test are related to the level of anxiety in mice." Neuropsychobiology 29(1): 23-27.

Gos, T., K. Gunther, H. Bielau, H. Dobrowolny, C. Mawrin, K. Trubner, R. Brisch, J. Steiner, H. G. Bernstein, Z. Jankowski and B. Bogerts (2009). "Suicide and depression in the quantitative analysis of glutamic acid decarboxylase-Immunoreactive neuropil." J Affect Disord 113(1-2): 45-55.

Gos, T., J. Steiner, H. Bielau, H. Dobrowolny, K. Gunther, C. Mawrin, M. Krzyzanowski, R. Hauser, R. Brisch, H. G. Bernstein, Z. Jankowski, K. Braun and B. Bogerts (2012). "Differences between unipolar and bipolar I depression in the quantitative analysis of glutamic acid decarboxylase-immunoreactive neuropil." Eur Arch Psychiatry Clin Neurosci 262(8): 647-655.

Hartmann, J., K. V. Wagner, C. Liebl, S. H. Scharf, X. D. Wang, M. Wolf, F. Hausch, T. Rein, U. Schmidt, C. Touma, J. Cheung-Flynn, M. B. Cox, D. F. Smith, F. Holsboer, M. B. Muller and M. V. Schmidt (2012). "The involvement of FK506-binding protein 51 (FKBP5) in the behavioral and neuroendocrine effects of chronic social defeat stress." Neuropharmacology 62(1): 332-339.

Huang, M. C., M. L. Schwandt, J. A. Chester, A. M. Kirchhoff, C. F. Kao, T. Liang, J. D. Tapocik, V. A. Ramchandani, D. T. George, C. A. Hodgkinson, D. Goldman and M. Heilig (2014). "FKBP5 moderates alcohol withdrawal severity: human genetic association and functional validation in knockout mice." Neuropsychopharmacology 39(8): 2029-2038. Isaac, J. T., R. A. Nicoll and R. C. Malenka (1995). "Evidence for silent synapses: implications for the expression of LTP." Neuron 15(2): 427-434.

Ising, M., A. M. Depping, A. Siebertz, S. Lucae, P. G. Unschuld, S. Kloiber, S. Horstmann, M. Uhr, B. Muller-Myhsok and F. Holsboer (2008). "Polymorphisms in the FKBP5 gene region modulate recovery from psychosocial stress in healthy controls." Eur J Neurosci 28(2): 389-398.

Kaufman, D. L., C. R. Houser and A. J. Tobin (1991). "Two forms of the gammaaminobutyric acid synthetic enzyme glutamate decarboxylase have distinct intraneuronal distributions and cofactor interactions." J Neurochem 56(2): 720-723.

Kutsuwada, T., K. Sakimura, T. Manabe, C. Takayama, N. Katakura, E. Kushiya, R. Natsume, M. Watanabe, Y. Inoue, T. Yagi, S. Aizawa, M. Arakawa, T. Takahashi, Y. Nakamura, H. Mori and M. Mishina (1996). "Impairment of suckling response, trigeminal neuronal pattern formation, and hippocampal LTD in NMDA receptor epsilon 2 subunit mutant mice." Neuron 16(2): 333-344. 
185

186

187

188

189

190

191

192

193

194

195

196

197

198

199

200

201

202

203

204

205

206

207

208

209

210

211

212

213

214

215

216

217

218

219

Lekman, M., G. Laje, D. Charney, A. J. Rush, A. F. Wilson, A. J. Sorant, R. Lipsky, S. R. Wisniewski, H. Manji, F. J. McMahon and S. Paddock (2008). "The FKBP5-gene in depression and treatment response--an association study in the Sequenced Treatment Alternatives to Relieve Depression (STAR*D) Cohort." Biol Psychiatry 63(12): 1103-1110. Levkovitz, Y., E. Avignone, Y. Groner and M. Segal (1999). "Upregulation of GABA neurotransmission suppresses hippocampal excitability and prevents long-term potentiation

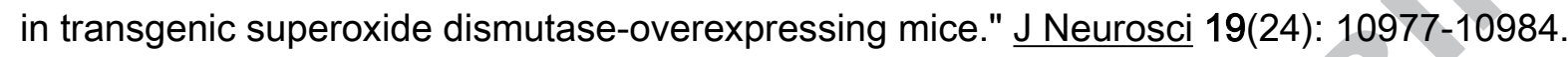
Levran, O., E. Peles, M. Randesi, Y. Li, J. Rotrosen, J. Ott, M. Adelson and M. J. Kreek (2014). "Stress-related genes and heroin addiction: a role for a functional FKBP5 haplotype."

\section{Psychoneuroendocrinology 45: 67-76.}

Li, Y., R. S. Erzurumlu, C. Chen, S. Jhaveri and S. Tonegawa (1994). "Whisker-related neuronal patterns fail to develop in the trigeminal brainstem nuclei of NMDAR1 knockout mice." Cell 76(3): 427-437.

Liao, D., N. A. Hessler and R. Malinow (1995). "Activation of postsynaptically silent synapses during pairing-induced LTP in CA1 region of hippocampal slice." Nature 375(6530): 400-404.

Lucki, I. (1997). "The forced swimming test as a model for core and component behavioral effects of antidepressant drugs." Behav Pharmacol 8(6-7): 523-532.

Luscher, B., Q. Shen and N. Sahir (2011). "The GABAergic deficit hypothesis of major depressive disorder." Mol Psychiatry 16(4): 383-406.

Maciag, D., J. Hughes, G. O'Dwyer, Y. Pride, C. A. Stockmeier, G. Sanacora and G.

Rajkowska (2010). "Reduced density of calbindin immunoreactive GABAergic neurons in the occipital cortex in major depression: relevance to neuroimaging studies." Biol Psychiatry 67(5): 465-470.

Mann, J. J. (2005). "The medical management of depression." N Engl J Med 353(17): 18191834.

McClintick, J. N., X. Xuei, J. A. Tischfield, A. Goate, T. Foroud, L. Wetherill, M. A. Ehringer and H. J. Edenberg (2013). "Stress-response pathways are altered in the hippocampus of chronic alcoholics." Alcohol 47(7): 505-515.

McClung, C. A., E. J. Nestler and V. Zachariou (2005). "Regulation of gene expression by chronic morphine and morphine withdrawal in the locus ceruleus and ventral tegmental area." J Neurosci 25(25): 6005-6015.

McHugh, T. J., K. I. Blum, J. Z. Tsien, S. Tonegawa and M. A. Wilson (1996). "Impaired hippocampal representation of space in CA1-specific NMDAR1 knockout mice." Cell 87(7): 1339-1349. 
Molendijk, M. L. and E. R. de Kloet (2015). "Immobility in the forced swim test is adaptive and does not reflect depression." Psychoneuroendocrinology 62: 389-391.

222

223

224

225

226

227

228

229

230

231

232

233

234

235

236

237

238

239

240

241

242

243

244

245

246

247

248

249

250

251

252

253

254

255

Moriyoshi, K., M. Masu, T. Ishii, R. Shigemoto, N. Mizuno and S. Nakanishi (1991).

"Molecular cloning and characterization of the rat NMDA receptor." Nature 354(6348): 31-37.

Nagatani, T., T. Sugihara and R. Kodaira (1984). "The effect of diazepam and of agents which change GABAergic functions in immobility in mice." Eur J Pharmacol 97(3-4): 271275.

Nagatani, T., T. Yamamoto, T. Sugihara and S. Ueki (1987). "The effect of agonists at the GABA-benzodiazepine receptor complex on the duration of immobility of mice in the forced swimming test." Eur J Pharmacol 142(1): 17-22.

Nakanishi, S. (1994). "Metabotropic glutamate receptors: synaptic transmission, modulation, and plasticity." Neuron 13(5): 1031-1037.

Nestler, E. J. (2001). "Molecular basis of long-term plasticity underlying addiction." Nat Rev Neurosci 2(2): 119-128.

Niehaus, J. L., M. Murali and J. A. Kauer (2010). "Drugs of abuse and stress impair LTP at inhibitory synapses in the ventral tegmental area." Eur J Neurosci 32(1): 108-117.

O'Leary, J. C., 3rd, S. Dharia, L. J. Blair, S. Brady, A. G. Johnson, M. Peters, J. CheungFlynn, M. B. Cox, G. de Erausquin, E. J. Weeber, U. K. Jinwal and C. A. Dickey (2011). "A new anti-depressive strategy for the elderly: ablation of FKBP5/FKBP51." PLoS One 6(9): e24840.

Pehrson, A. L. and C. Sanchez (2015). "Altered gamma-aminobutyric acid neurotransmission in major depressive disorder: a critical review of the supporting evidence and the influence of serotonergic antidepressants." Drug Des Devel Ther 9: 603-624.

Pelz, W. E., G. Whitney and J. C. Smith (1973). "Genetic influences on saccharin preference of mice." Physiol Behav 10(2): 263-265.

Pinal, C. S. and A. J. Tobin (1998). "Uniqueness and redundancy in GABA production." Perspect Dev Neurobiol 5(2-3): 109-118.

Porsolt, R. D., M. Le Pichon and M. Jalfre (1977). "Depression: a new animal model sensitive to antidepressant treatments." Nature 266(5604): 730-732.

Qiu, B., S. E. Luczak, T. L. Wall, A. M. Kirchhoff, Y. Xu, M. Y. Eng, R. B. Stewart, W. Shou, S. L. Boehm, J. A. Chester, W. Yong and T. Liang (2016). "The FKBP5 Gene Affects Alcohol Drinking in Knockout Mice and Is Implicated in Alcohol Drinking in Humans." Int J Mol Sci 17(8).

Rajkowska, G., G. O'Dwyer, Z. Teleki, C. A. Stockmeier and J. J. Miguel-Hidalgo (2007). "GABAergic neurons immunoreactive for calcium binding proteins are reduced in the prefrontal cortex in major depression." Neuropsychopharmacology 32(2): 471-482. 
Reynolds, P. D., Y. Ruan, D. F. Smith and J. G. Scammell (1999). "Glucocorticoid resistance in the squirrel monkey is associated with overexpression of the immunophilin FKBP51." $\underline{J}$ Clin Endocrinol Metab 84(2): 663-669.

Riss, J., J. Cloyd, J. Gates and S. Collins (2008). "Benzodiazepines in epilepsy: pharmacology and pharmacokinetics." Acta Neurol Scand 118(2): 69-86. (2011). "A systems genetic analysis of alcohol drinking by mice, rats and men: influence of brain GABAergic transmission." Neuropharmacology 60(7-8): 1269-1280.

Sajdyk, T., P. Johnson, S. Fitz and A. Shekhar (2008). "Chronic inhibition of GABA synthesis in the bed nucleus of the stria terminalis elicits anxiety-like behavior." J Psychopharmacol 22(6): 633-641.

Sanacora, G. and A. Saricicek (2007). "GABAergic contributions to the pathophysiology of depression and the mechanism of antidepressant action." CNS Neurol Disord Drug Targets 6(2): 127-140.

Scharf, S. H., C. Liebl, E. B. Binder, M. V. Schmidt and M. B. Muller (2011). "Expression and regulation of the Fkbp5 gene in the adult mouse brain." PLoS One 6(2): e16883. Schiene, C. and G. Fischer (2000). "Enzymes that catalyse the restructuring of proteins." Curr Opin Struct Biol 10(1): 40-45. Schmidt, U., D. R. Buell, I. A. Ionescu, N. C. Gassen, F. Holsboer, M. B. Cox, B. Novak, C. Huber, J. Hartmann, M. V. Schmidt, C. Touma, T. Rein and L. Herrmann (2015). "A role for synapsin in FKBP51 modulation of stress responsiveness: Convergent evidence from animal and human studies." Psychoneuroendocrinology 52: 43-58. (2011). "Direct Corticosteroid Modulation of GABAergic Neurons in the Anterior Hypothalamic Area of GAD65-eGFP Mice." Korean J Physiol Pharmacol 15(3): 163-169. why?" Trends Pharmacol Sci 19(12): 500-505.

Stechschulte, L. A. and E. R. Sanchez (2011). "FKBP51-a selective modulator of glucocorticoid and androgen sensitivity." Curr Opin Pharmacol 11(4): 332-337. Sugihara, H., K. Moriyoshi, T. Ishii, M. Masu and S. Nakanishi (1992). "Structures and properties of seven isoforms of the NMDA receptor generated by alternative splicing." Biochem Biophys Res Commun 185(3): 826-832. 
Szczepankiewicz, A., A. Leszczynska-Rodziewicz, J. Pawlak, B. Narozna, A. Rajewska-

292

293

294

295

296

297

298

299

300

301

302

303

304

305

306

307

308

309

310

311

312

313

314

315

316

317

318

319

320

321

322

323

324

325

326

Rager, M. Wilkosc, D. Zaremba, M. Maciukiewicz and J. Twarowska-Hauser (2014). "FKBP5 polymorphism is associated with major depression but not with bipolar disorder." $\mathrm{J}$ Affect Disord 164: 33-37.

Szymanska, M., B. Budziszewska, L. Jaworska-Feil, A. Basta-Kaim, M. Kubera, M. Leskiewicz, M. Regulska and W. Lason (2009). "The effect of antidepressant drugs on the HPA axis activity, glucocorticoid receptor level and FKBP51 concentration in prenatally stressed rats." Psychoneuroendocrinology 34(6): 822-832.

Tang, Y. P., E. Shimizu, G. R. Dube, C. Rampon, G. A. Kerchner, M. Zhuo, G. Liu and J. Z. Tsien (1999). "Genetic enhancement of learning and memory in mice." Nature 401(6748): 63-69.

Tatro, E. T., I. P. Everall, E. Masliah, B. J. Hult, G. Lucero, G. Chana, V. Soontornniyomkij, C. L. Achim and H. I. V. N. R. Center (2009). "Differential expression of immunophilins FKBP51 and FKBP52 in the frontal cortex of HIV-infected patients with major depressive disorder." J Neuroimmune Pharmacol 4(2): 218-226.

Tatro, E. T., T. B. Nguyen, C. A. Bousman, E. Masliah, I. Grant, J. H. Atkinson and I. P. Everall (2010). "Correlation of major depressive disorder symptoms with FKBP5 but not FKBP4 expression in human immunodeficiency virus-infected individuals." J Neurovirol 16(5): 399-404.

Touma, C., N. C. Gassen, L. Herrmann, J. Cheung-Flynn, D. R. Bull, I. A. Ionescu, J. M. Heinzmann, A. Knapman, A. Siebertz, A. M. Depping, J. Hartmann, F. Hausch, M. V. Schmidt, F. Holsboer, M. Ising, M. B. Cox, U. Schmidt and T. Rein (2011). "FK506 binding protein 5 shapes stress responsiveness: modulation of neuroendocrine reactivity and coping behavior." Biol Psychiatry 70(10): 928-936.

Treadwell, J. A. and S. M. Singh (2004). "Microarray analysis of mouse brain gene expression following acute ethanol treatment." Neurochem Res 29(2): 357-369.

Tsien, J. Z., P. T. Huerta and S. Tonegawa (1996). "The essential role of hippocampal CA1 NMDA receptor-dependent synaptic plasticity in spatial memory." Cell 87(7): 1327-1338. Wagner, K. V., D. Marinescu, J. Hartmann, X. D. Wang, C. Labermaier, S. H. Scharf, C. Liebl, M. Uhr, F. Holsboer, M. B. Muller and M. V. Schmidt (2012). "Differences in FKBP51 regulation following chronic social defeat stress correlate with individual stress sensitivity: influence of paroxetine treatment." Neuropsychopharmacology 37(13): 2797-2808.

Westberry, J. M., P. W. Sadosky, T. R. Hubler, K. L. Gross and J. G. Scammell (2006). "Glucocorticoid resistance in squirrel monkeys results from a combination of a transcriptionally incompetent glucocorticoid receptor and overexpression of the glucocorticoid receptor co-chaperone FKBP51." J Steroid Biochem Mol Biol 100(1-3): 34-41. 
327 Wigstrom, H. and B. Gustafsson (1983). "Facilitated induction of hippocampal long-lasting 328 potentiation during blockade of inhibition." Nature 301(5901): 603-604.

329 Willour, V. L., H. Chen, J. Toolan, P. Belmonte, D. J. Cutler, F. S. Goes, P. P. Zandi, R. S.

330 Lee, D. F. MacKinnon, F. M. Mondimore, B. Schweizer, J. R. DePaulo, Jr., E. S. Gershon, F.

331 J. McMahon and J. B. Potash (2009). "Family-based association of FKBP5 in bipolar

332 disorder." Mol Psychiatry 14(3): 261-268.

333 Wolf, M. E. (2003). "LTP may trigger addiction." Mol Interv 3(5): 248-252.

334 Xie, P., H. R. Kranzler, J. Poling, M. B. Stein, R. F. Anton, L. A. Farrer and J. Gelernter

335 (2010). "Interaction of FKBP5 with childhood adversity on risk for post-traumatic stress

336 disorder." Neuropsychopharmacology 35(8): 1684-1692.

337 Yong, W., Z. Yang, S. Periyasamy, H. Chen, S. Yucel, W. Li, L. Y. Lin, I. M. Wolf, M. J.

338 Cohn, L. S. Baskin, E. R. Sanchez and W. Shou (2007). "Essential role for Co-chaperone

339 Fkbp52 but not Fkbp51 in androgen receptor-mediated signaling and physiology." $\underline{\mathrm{J} \text { Biol }}$

340 Chem 282(7): 5026-5036.

341

342

Highlights of Fkbp5 KO mice electrophysiology research

343

- LTP reduced in Fkbp5 KO male mice relative to WT, indicating altered neuron function.

345

- Expression of excitatory glutamate receptors (NMDAR1, NMDAR2B, and AMPAR) and $\mathrm{mEPSC}$ frequency reduced in $\mathrm{KO}$.

- Increased GABA expression and mIPSC frequency in KO hippocampus.

- Male Fkbp5 KO mice display low saccharin intake and higher immobility 


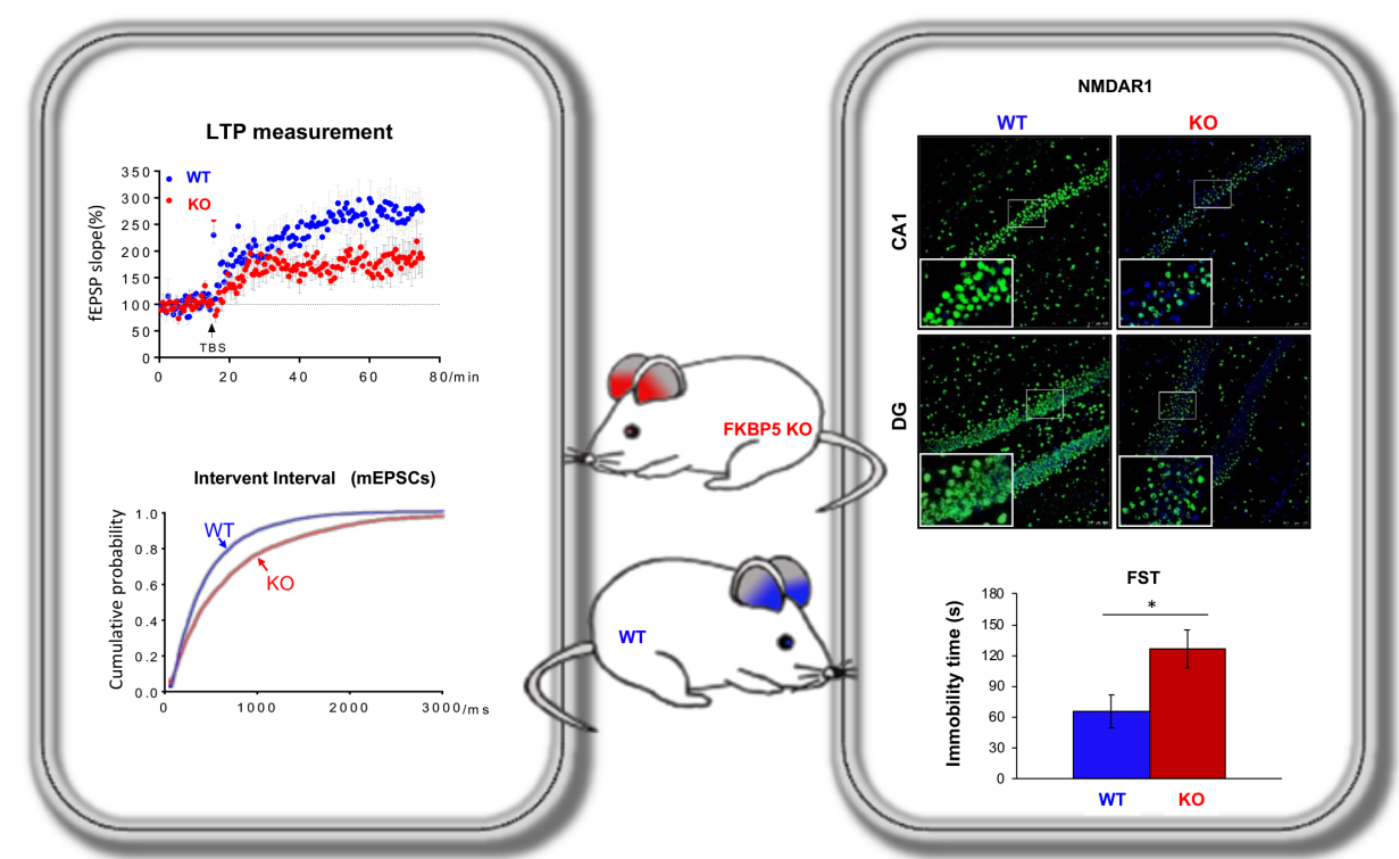

A
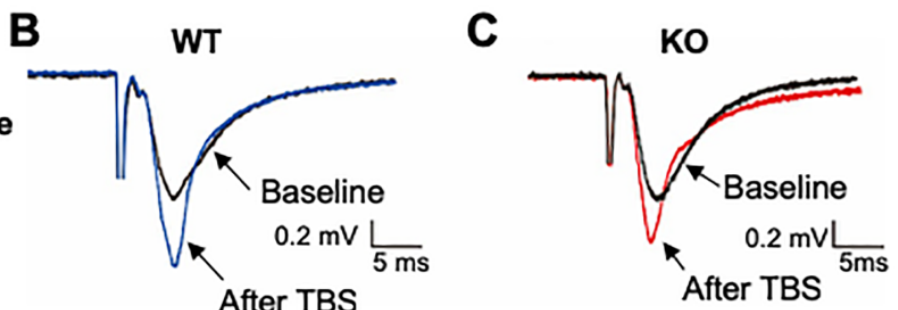

D

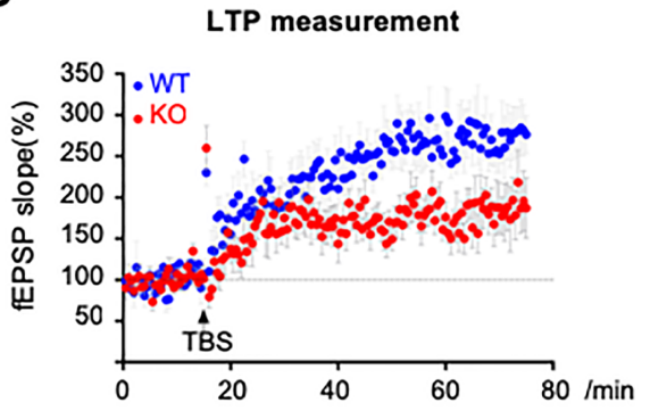

E LTP measurement

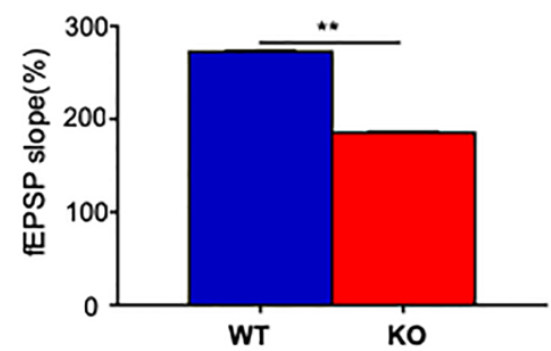

Fig. 1 
A

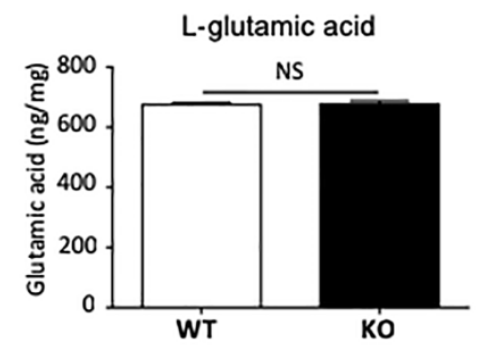

B

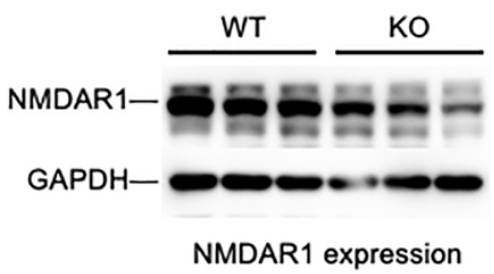

C
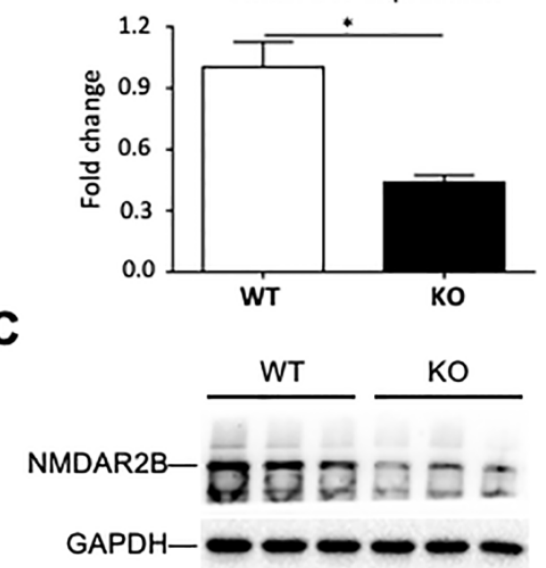

D

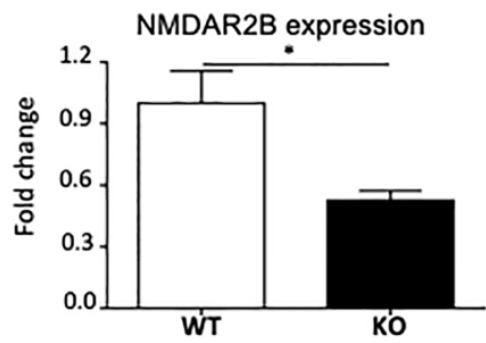

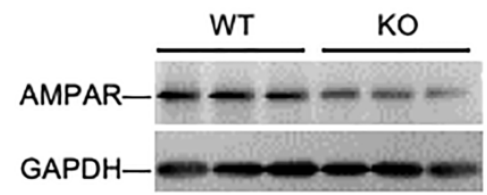

AMPAR expression

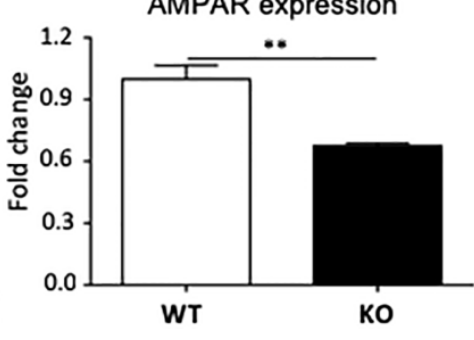

Fig. 2
E

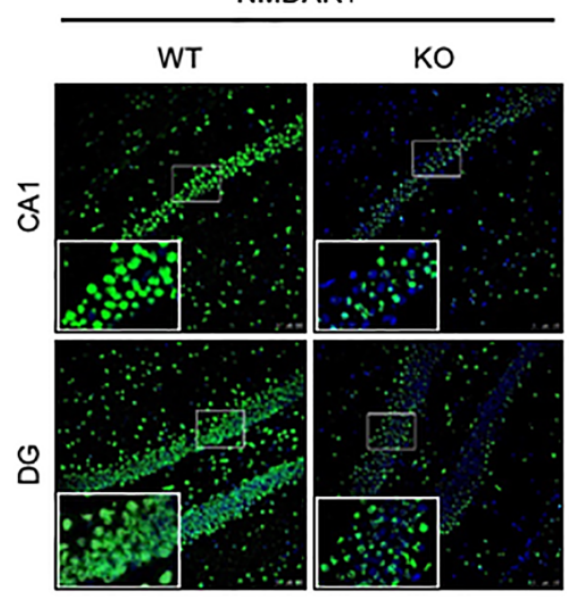

$\mathbf{F}$
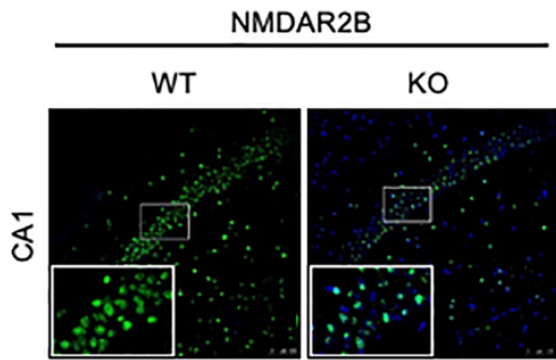

Oㅁ

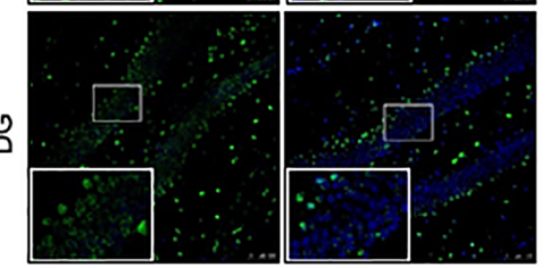

G
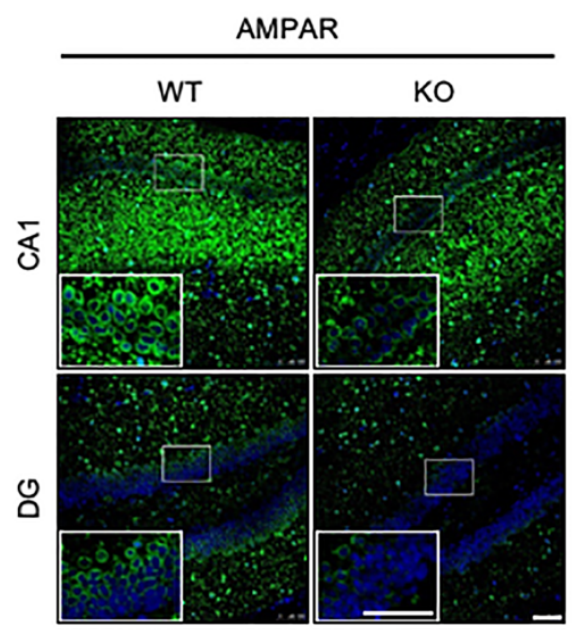
A

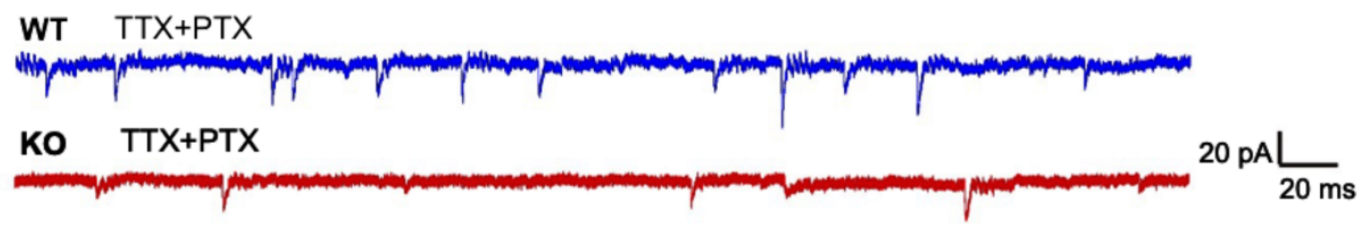

B

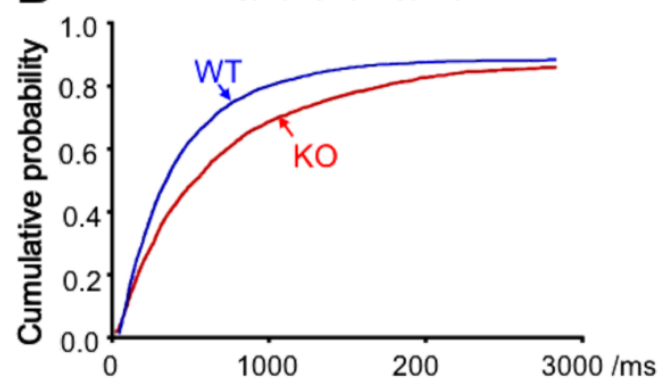

C

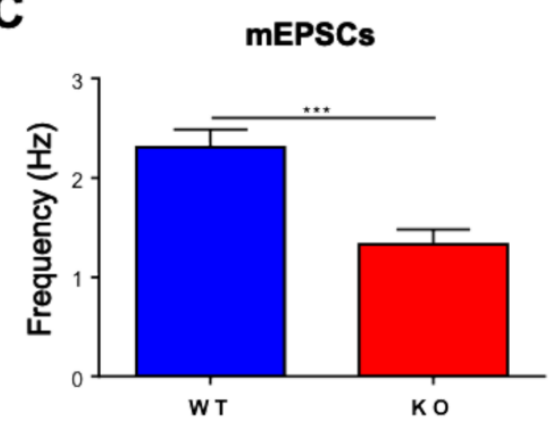

D Amplitude

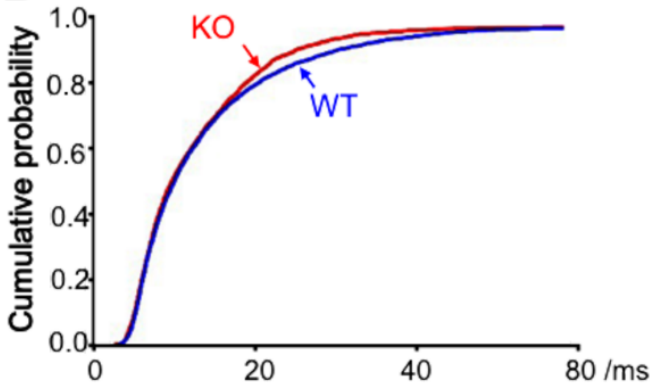

E

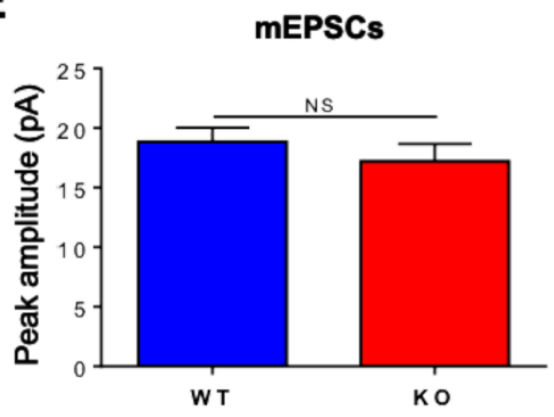

Fig. 3 

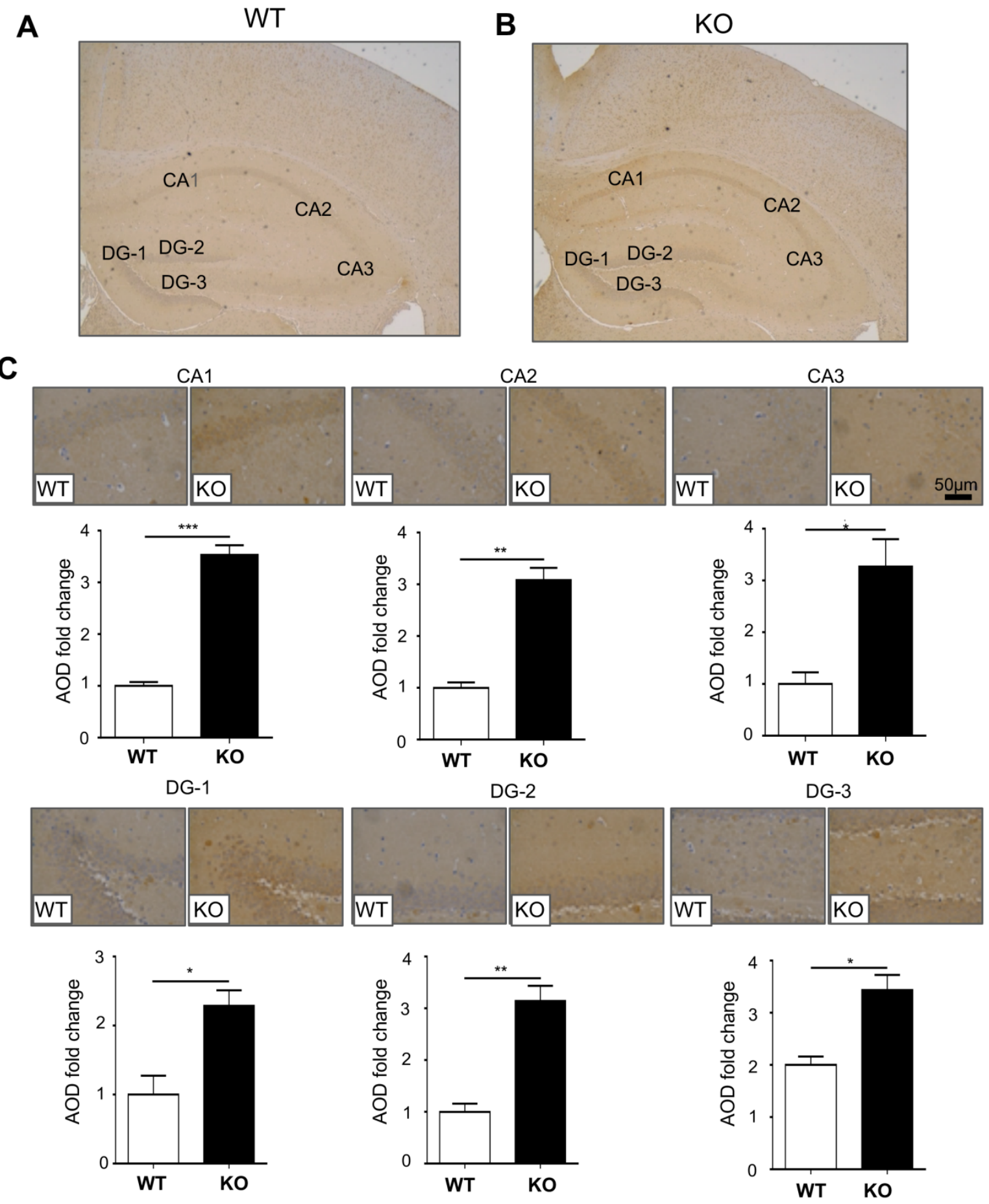

Fig. 4 
A

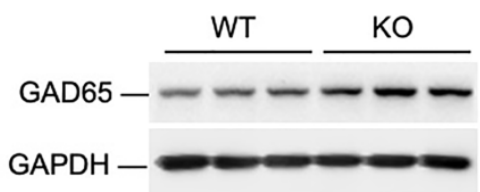

GAD67 expression

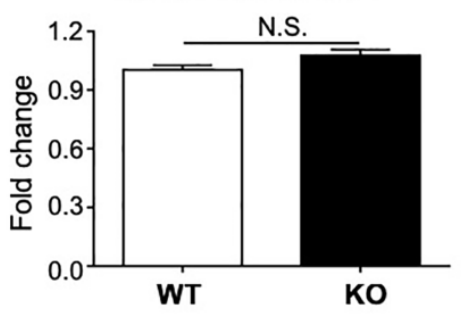

B

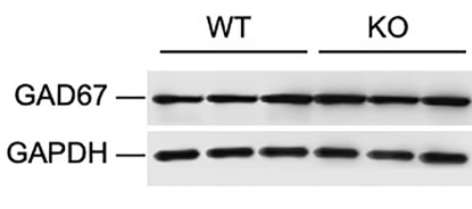

GAD65 expression

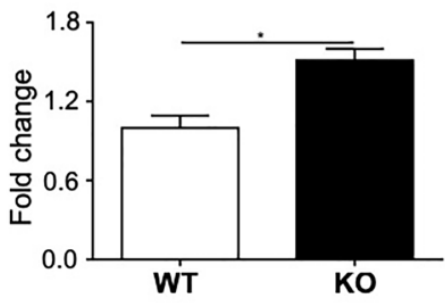

C

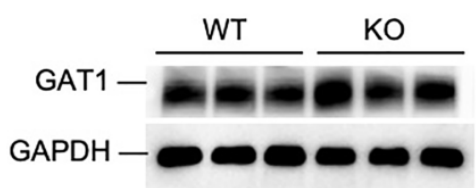

GAT1 expression

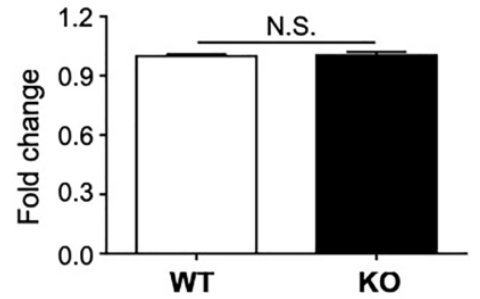

Fig.5

A

TTX+CNQX+D-AP5 WT

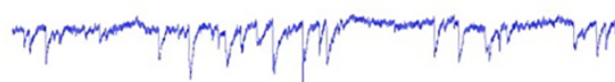

+ Bicuculline

B

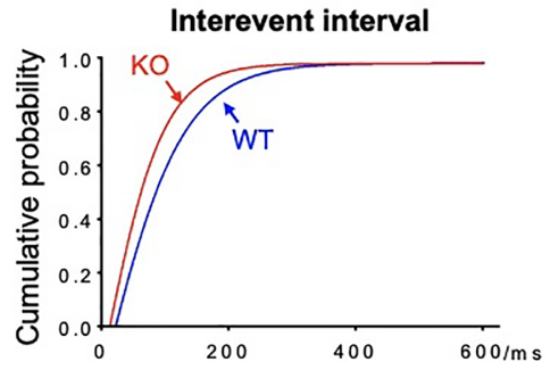

C mIPSCs of GABAergic synapses

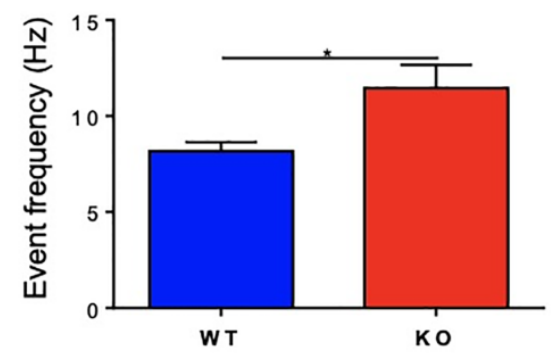

TTX+CNQX+D-AP5 KO

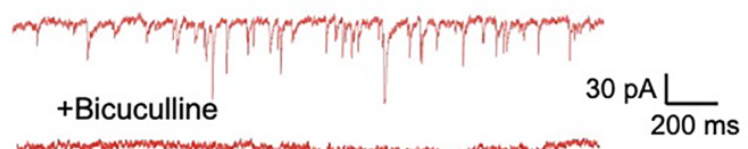

D

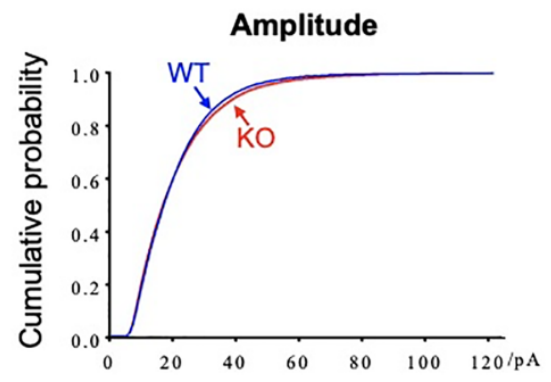

E mIPSCs of GABAergic synapses

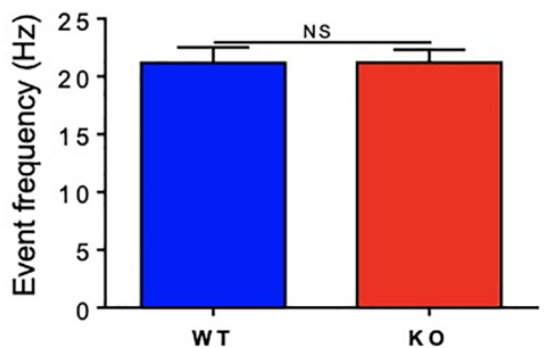

Fig. 6 
A

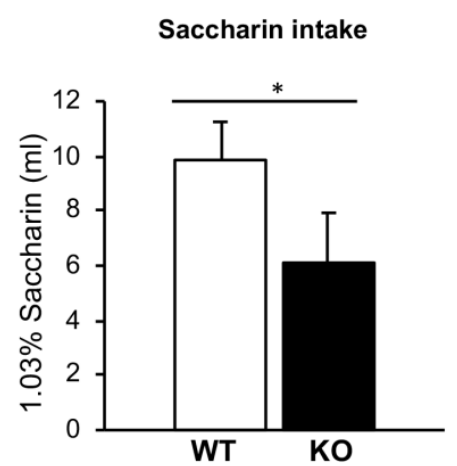

B

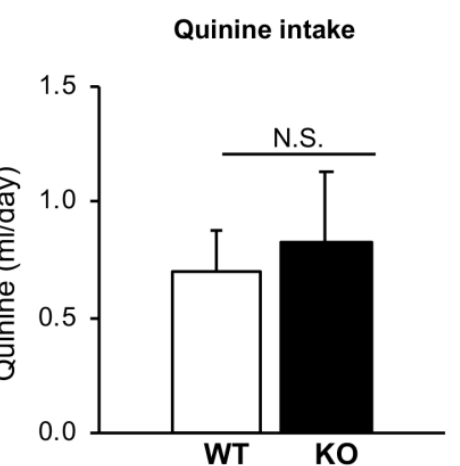

C

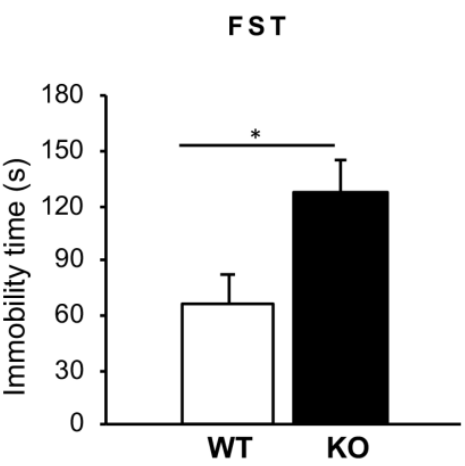

Fig. 7 